\title{
A ATUALIDADE DA METODOLOGIA ANARQUISTA DE EDUCAÇÃO: REFLEXÕES ACERCA DO CONSTRUTIVISMO E DA PÓS-MODERNIDADE ${ }^{1}$
}

\author{
Profa. Msc. Juliana Guedes dos Santos Marconi ${ }^{2}$ \\ (julianaguedes_ufscar@yahoo.com.br) \\ Prof. Dr. Luiz Bezerra Neto ${ }^{3}$ \\ (lbezerra@ufscar.br)
}

Resumo: Sem a pretensão de comparar ou fazer aproximações entre as educações proferidas e defendidas pelos anarquistas e qualquer outra nos dias atuais, busca-se neste texto refletir acerca da atualidade da metodologia anarquista de educação a partir da análise desta em relação às teorias construtivistas de educação. O texto inicia com a explanação acerca das teorias que compõem o caminho histórico desde meados do século XVIII, quando o anarquismo começa a dar os primeiros passos, até o início do século XXI, quando despontam as teorias pós-modernas de educação. Com relação ao anarquismo, lida-se aqui com as vertentes que mais explicitam o idealismo contemporâneo de seu desenvolvimento já que sugerem a educação como ferramenta principal de transformação social. Em seguida, trata-se da disseminação de tais teorias educacionais no Brasil e da chegada dos ideais escolanovistas no país, contemporaneamente ao fechamento das instituições paulistas de educação anarquista. A evolução dos ideais escolanovistas para o construtivismo permite a continuidade da trajetória desembocando, por fim, em uma breve análise da atual transição para as teorias pós-modernas de educação. Esse caminho permitiu o levantamento de cinco categorias que evidenciam a presença dos ideais anarquistas de educação no contexto brasileiro atual, sendo a) A psicologia infantil e o foco no indivíduo; b) A relação entre jogo e trabalho; c) A experiência como atividade fundamental no processo educativo; d) A importância do meio

\footnotetext{
${ }^{1}$ Artigo resultante da dissertação apresentada ao Programa de Pós-Graduação em Educação da Universidade Federal de São Carlos (PPGE-UFSCar) como requisito para a obtenção do título de mestre em Fundamentos da Educação da primeira autora. A pesquisa foi financiada pela Coordenação de Aperfeiçoamento de Pessoal de Nível Superior (CAPES).

${ }^{2}$ Doutoranda em História, Filosofia e Sociologia da Educação pelo Programa de Pós-Graduação em Educação da Universidade Federal de São Carlos (PPGE-UFSCar) e professora da Escola Superior de Tecnologia e Educação de Porto Ferreira (ASSER).

${ }^{3}$ Doutor em Educação pela Universidade Estadual de Campinas (UNICAMP) e professor adjunto do Departamento de Educação da Universidade Federal de São Carlos (UFSCar).
} 
social e/ou comunitário; e) O papel do educador. No caminhar do século XVIII ao XXI, espera-se, portanto, incitar a discussão sobre a atualidade da metodologia anarquista de educação, mostrando que o passado faz-se cada vez mais presente no cenário educacional.

Palavras-chave: Anarquismo; Construtivismo; metodologia educacional.

Abstract: Without the pretension to compare or to make approaches between the proffered and defended educations by the anarchists and any another tendency in the current days, the aim, in this text is a reflection about the current anarchist methodology of education from this analysis in relation to the constructivists theories of education. The text begins with an explanation about the theories that compose the historical way since the middle of century XVIII, when the anarchism starts to give the first steps, till the beginning of century XXI, when the after-modern theories of education blunt. In accordance the anarchism, we are working, here, with the sources that more put in evidence the contemporary idealism in its development since they suggest the education as main tool of social transformation. After that, the point is the dissemination of such educational theories in Brazil and the arrival of the escolanovistas ideals here, contemporarily to the closing of São Paulo institutions of anarchic education. The evolution from the escolanovistas ideals to the constructivism allows the continuity of this trajectory discharging, finally, in one brief analysis of the current transition of the after-modern theories of education. This way allowed the survey of five categories that evidence the presence of the anarchic ideals of education in the current Brazilian context, being: a) infantile psychology and the focus in the individual; b) The relation between game and work; c) The experience as basic activity in the educative process; d) The importance of the social environment and/or communitarian; e) The paper of the educator. In walking of century XVIII to the XXI, one expects, therefore, stirring up the quarrel on the present time of the anarchic methodology of education, showing that the past becomes each more present in the educational scene.

Keywords: Anarchism; Constructivism; educational methodology..

A participação da Professora Ana Elisa Siqueira (diretora da EMEF Desembargador Amorim Lima, cuja metodologia fora transformada com base na experiência da Escola da Ponte, em Portugal) e de José Pacheco (coordenador da instituição portuguesa), durante o I 
Colóquio Internacional de Educação Libertária, promovido pelo Instituto de Estudos Libertários (IEL), em São Paulo, nos permite questionar se estaríamos revivendo a disseminação de iniciativas anarquistas na Europa e no Brasil. Além disso, a declaração no Projeto Pedagógico da instituição representada por José Pacheco, que afirma possuir um currículo "cruzado com metodologias próximas do paradigma construtivista” (ESCOLA da Ponte, 2007, p. 6) permite que se indague a existência de proximidades entre as concepções anarquista e construtivista de educação.

No entanto, como o contexto histórico e as inegáveis diferenças político-ideológicas que fundamentam as concepções anarquistas e construtivistas de educação impedem qualquer tentativa de comparação ou aproximações entre as educações proferidas e defendidas por elas, o foco da pesquisa se deu na metodologia, nas ferramentas necessárias à execução do trabalho pedagógico, na prática do processo ensino-aprendizagem.

Isso posto, procurou-se traçar um caminho histórico que permita refletir sobre a atualidade da metodologia anarquista. Tal caminho começa em meados do século XVIII quando o anarquismo começa a dar os primeiros passos. Lidaremos aqui com as vertentes que mais explicitam o idealismo contemporâneo de seu desenvolvimento porque são elas que nos sugerem a educação como ferramenta principal de transformação social; lidaremos, portanto, com as teorias de Pierre-Joseph Proudhon, Max Stirner e Leon Tolstoi. A continuação do caminho está na disseminação de tais teorias educacionais no Brasil e na chegada dos ideais escolanovistas no país contemporaneamente ao fechamento das instituições paulistas de educação anarquista. O crescimento dos ideais escolanovistas e a evolução destes para o construtivismo nos permitem a continuidade da trajetória deste texto. Por fim, a análise da atual transição para as teorias pós-modernas de educação nos permitiram elencar cinco categorias que evidenciam a presença dos ideais anarquistas de educação no contexto brasileiro atual. São elas: 1. A psicologia infantil e o foco no indivíduo; 2. A relação entre jogo e trabalho; 3. A experiência como atividade fundamental no processo educativo; 4. A importância do meio social e/ou comunitário; e 5. O papel do educador.

Espera-se, portanto, incitar a discussão sobre a atualidade da metodologia anarquista de educação caminhando historicamente do século XVIII ao XXI, percebendo que o passado pode se fazer cada vez mais presente no cenário educacional. 


\section{O caminho: Anarquismo, Escola Nova, Construtivismo e Pós-Modernidade}

O conceito de educação foi se transformando com o passar dos séculos e, de forma inversamente proporcional, enquanto seu raio de abrangência se expandia - através da democratização do acesso à educação - o foco do processo educativo se reduzia, dirigindo-se, cada vez mais, para o aluno, enquanto sujeito, ou seja, a formação individualizada daqueles a quem se dirigia o trabalho pedagógico passava a ser o fim da educação.

Essa transformação teve início no período do Iluminismo e, por serem as teorias anarquistas contemporâneas a ele, também objetivavam a formação de um indivíduo autônomo (através da ilustração) e educado para viver na Modernidade que se aproximava. A ilustração, o conhecimento, as luzes, facilitariam a adaptação e atuação dos indivíduos na nova sociedade, modernizada pelas revoluções Industrial e Francesa.

Independente da vertente ${ }^{4}$ a que pertencem, os ideais anarquistas sempre focaram o mesmo objetivo: a sociedade sem Estado. Além disso, estiveram carregados de idealismo principalmente por conta da importância atribuída à educação (vista como ferramenta fundamental de transformação social), pelo movimento da propaganda pela ação ${ }^{5}$, e pela possibilidade de atuação coletiva e individual. Assim, embora as teorias anarquistas de educação tenham surgido em meio a essas ideias, a superação da sociedade que se consolidava era o fim comum. As teorias reconheciam, ao mesmo tempo, a importância da

\footnotetext{
${ }^{4}$ Individualistas: almejavam uma sociedade livre com base na justiça abstrata - representados por Max Stirner e William Godwin, este último, considerado por Codello como “pai do anarquismo” (CODELLO, 2007, p. 29) é, em contrapartida, pouco reconhecido pelos educadores libertários; Mutualistas: pensavam mais em termos de associação - o maior nome entre os mutualistas foi o de Pierre Joseph-Proudhon; Coletivistas: almejavam ver a propriedade em mãos de instituições voluntárias, assegurando aos trabalhadores o direito de desfrutar do produto de seu trabalho - têm como representante Michael Bakunin que, segundo Woodcock, foi o maior disseminador das ideias de Proudhon. Segundo o autor, a obra de Proudhon "dificilmente poderia ter se manifestado sob o comando do mais espetacular e herético de seus discípulos, Michael Bakunin” (WOODCOCK, 2002, p. 164); Anarco-comunistas: tinham como base o lema: "De cada um, de acordo com seus meios; a cada um, de acordo com suas necessidades” (WOODCOCK, 2002, p. 21) e não de acordo com seus direitos - Peter Kropotkin representa os anarco-comunistas e apóia-se na ideia de que revolução é um processo natural e não violento, “mais simpática do que a concepção bakuniana de revolução como apocalipse” (WOODCOCK, 2002, p. 214). Anarcossindicalistas: viam na organização operária (em sindicatos e na greve geral) suas armas mais poderosas. Tolstoísmo: repudiavam a violência embora se opusessem com veemência ao Estado e a outras formas de autoridade e atuavam na criação de comunidades libertárias agrícolas.

${ }^{5}$ O termo propaganda pela ação é geralmente atribuído a pequenas revoltas locais lideradas por anarquistas como uma forma de estímulo pelo exemplo. Segundo Woodcock, os líderes dessas revoltas faziam-nas "não porque acreditassem que elas poderiam dar origem a revoluções que ficariam sobre seu controle, mas porque viam essas ações como ‘propaganda pela ação’” (WOODCOCK, 2002, p. 18).
} 
educação no desenvolvimento da autonomia dos indivíduos e viam essa autonomia como a base para a luta em prol da superação da sociedade hierarquizada em preferência à sociedade autorregulada. Em outras palavras, os anarquistas objetivavam a formação da geração que faria a revolução social embasados no conceito de que qualquer revolução econômica e/ou política não aconteceria antes e/ou separadamente da revolução social.

Os estudos e escritos de Max Stirner, Pierre-Joseph Proudhon e Leon Tolstoi, cada qual em sua vertente, nos permitiram a análise do idealismo anarquista. Stirner, nome sob o qual ficou conhecido Johann Caspar Schmidt (1806-1856), é considerado “o egoísta” por Woodcock já que "negava todos os absolutos e todas as instituições, baseando-se unicamente na 'singularidade’ do indivíduo” (WOODCOCK, 2002, p. 105). Sua incessante busca da formação da personalidade do indivíduo está no fato de defender a ideia de que "a única regra de conduta a ser seguida pelo indivíduo serão suas próprias necessidades e desejos” (WOODCOCK, 2002, p. 112). Com base nesta regra única, a educação para Stirner é a “nutrição do espírito, como um modo de personalização do saber, como meio para a formação do caráter” (FERRER, 2001, p. 19 - grifo do autor). O processo de enisoaprendizagem, segundo sua teoria, acontece da seguinte forma: ao atingir o nível do Saber, deve-se matá-lo e ressuscitá-lo como Vontade. A Vontade permite a formação da personalidade e, se se para no estágio do Saber, o indivíduo é formado a partir de padrões estabelecidos se adequando aos mesmos. Ao atingir-se o nível da Vontade, os indivíduos desenvolvem a personalidade. Ela é, portanto, o ponto de partida e objetivo final da educação para Stirner:

numa palavra, não se deve inculcar o saber mas conduzir o indivíduo a seu pleno desenvolvimento; a pedagogia não pode mais partir da idéia de civilizar, mas da idéia de desenvolver pessoas livres, caracteres soberanos. É preciso, então, cessar de enfraquecer a Vontade, até o presente sempre tão brutalmente oprimida (STIRNER, 2001, p. 81).

Assim, já que a educação, segundo Stirner, é a ferramenta pela qual se atinge o estágio da Vontade ela também pode aqui ser entendida como ferramenta para promover a transformação social. Por valorizar o conhecimento como nutrição do espírito e formação da personalidade - ferramentas necessárias à emancipação da sociedade - o idealismo presente nas ideias de Stirner é explícito. 
Pierre Joseph Proudhon (1809-1865), o primeiro a reclamar para si o título de anarquista em sua mais famosa obra “O que é propriedade?” (1840), foi caracterizado por Woodcock como “o homem dos paradoxos”. Além disso, Proudhon considera o indivíduo como ponto de partida e objetivo final de todas as ações sociais. Sua análise é alicerçada sempre no equilíbrio entre os lados bom e mau de seus objetos de análise. Na análise da propriedade, Proudhon deixa claro o idealismo de suas ideias. Segundo ele, "nem o trabalho, nem a ocupação nem a lei podem criar a propriedade; (...) ela é um efeito sem causa” (PROUDHON, 1998, p. 21).

Referindo-se à educação, à necessidade de instrução dos povos e a importância disso para a evolução da sociedade, Proudhon afirma que "à medida que a sociedade fica mais esclarecida a autoridade real diminui: este é um fato de que toda a História dá testemunho” (PROUDHON, 1998, p. 28). No entanto, a importância da ciência, da educação, da instrução, como ferramentas de emancipação, representa o ponto de partida para a análise completa feita por ele. Nas palavras do autor,

\begin{abstract}
à força de se instruir e de adquirir idéias, o homem acabou por adquirir a idéia da ciência, quer dizer, a idéia de um sistema de conhecimento conforme a realidade das coisas e deduzido da observação. Ele procura então ou a ciência ou um sistema de corpos brutos, em sistema de corpos organizados, um sistema do espírito humano, um sistema do mundo: como não procuraria também um sistema da sociedade? Mas, tendo chegado a este ponto, ele compreende que a verdade ou a ciência política são coisas completamente independentes da vontade soberana, da opinião das maiorias e das crenças populares, que reis, ministros e povos, enquanto vontades, não são nada para a ciência e não merecem consideração alguma (PROUDHON, 1998, p. 29).
\end{abstract}

Os escritos de Proudhon embasaram teoricamente Leon Tolstoi (1828-1910), que pregava "uma revolução moral, mais do que uma revolução política (...) através da razão e, basicamente, através da persuasão e do exemplo” (WOODCOCK, 2002, p. 270), mas, ao contrário do primeiro, não aceitava o rótulo de anarquista "porque aplicava esse termo àqueles que desejavam transformar a sociedade utilizando métodos violentos; preferia considerar-se um cristão liberal” (WOODCOCK, 2002, p. 257). Títulos e rótulos a parte, Tolstoi pondera que Proudhon "foi o único homem que compreendeu a importância da instrução popular e da imprensa na nossa época” (TOLSTOI, 1988, p. 33).

Tolstoi participou de experiências educativas libertárias nas quais havia um "tipo de colaboração espontânea entre professores e alunos” (WOODCOCK, 2002, p. 263). Essa 
experiência que, segundo Tatiana Calsavara, durou entre 1858 e 1862, aconteceu na fazenda do próprio Tosltoi: a Iasnaia Poliana. "Em seus escritos e em sua prática pedagógica, Tolstoi proclama o princípio da liberdade e procura enxergar a educação do ponto de vista da criança” (CALSAVARA, 2004, p. 52). Ademais, a instituição "não tinha regras formuladas em forma de leis. As regras deveriam ser espontâneas, surgidas na necessidade da convivência. Ele acreditava que de uma desordem social, a organização nasceria naturalmente, sem necessidade de nenhum sistema de controle” (CALSAVARA, 2004, p. 52).

Uma das principais críticas de Tolstoi à educação de sua época é o fato de que as escolas não são feitas às crianças. Para ele, "a escola não é instituída para que às crianças seja cômodo estudar, mas que aos professores seja cômodo ensinar. Ao professor incomodam os ruídos, o movimento e a alegria das crianças, que são para elas uma condição indispensável de estudo” (TOLSTOI, 1988, p. 46).

Esse direcionamento da educação escolar ao indivíduo que nela aprende, à criança, cujo objetivo é a formação de mentes criativas e o desenvolvimento de suas personalidades, alicerçou teoricamente o movimento anarquista de educação como um todo, representado, principalmente pelas “escolas modernas”.

Este movimento foi representado na Espanha pela La Escuela Moderna de Barcelona, idealizada e dirigida por Francisco Ferrer y Guardia e, segundo Silvio Gallo, inspirada na experiência de Tolstoi. A escola funcionou por cinco anos (1901-1906) e foi fechada por causa da repressão religiosa e política à Ferrer depois de um atentado à bomba no casamento do rei Afonso XIII.

O autor do atentado [Mateo Morale] trabalhou por um pequeno período na livraria da Escola Moderna, motivo que foi usado para prender Ferrer e todos os professores, além de cerrar as portas da escola. Ferrer foi vítima de calúnia promovida pela Igreja católica, sendo acusado de cúmplice no atentado. Mesmo tratamento foi dado à sua escola e ao sistema de ensino, acusado de ser "sem Deus" e de contar com revistas e livros indecentes (MORAES, 2009, p. 1).

No Brasil tais teorias chegaram com os imigrantes e foram colocadas em prática, sobretudo, nas Escolas Modernas $\mathrm{n}^{0} 1$ e 2, fundadas nos anos de 1912 e 1913, respectivamente, na cidade de São Paulo e inspiradas na iniciativa barcelonesa e, nos permite ver como os ideais anarquistas desenvolveram-se no Brasil do início do século XX. Dessa forma, as principais características metodológicas das escolas anarquistas europeias, 
principalmente da instituição barcelonesa, foram aplicadas no Brasil com dificuldades e fidelidade. Entre as características destacam-se: a co-educação de sexos e classes sociais; o incentivo à higiene; a não aceitação do ensino religioso e das características advindas desse tipo de educação; a presença das famílias nas escolas; a valorização do ensino pela experiência e a criação de periódicos próprios.

A importância da imprensa na educação extrapolou os muros das Escolas Modernas brasileiras ao passo que elas não apenas fundaram os próprios periódicos como contaram com o apoio de jornais operários na divulgação do trabalho desenvolvido e na angariação de recursos. Em publicação do jornal A Lanterna, a valorização dos conceitos da educação racionalista fica explícita na reportagem/anúncio da Escola Moderna n² 2 . Segue a transcrição:

Scientificamos ás famílias que se acha instalada no prédio da rua Müller, 74, a Escola moderna $\mathrm{n}^{0}$ 2, criada sob os auspícios do Comitê Pró-Escola Moderna. Esta Escola servir-se-há do método inductivo demonstrativo e objectivo, e basear-se-há na esperimentação, nas afirmações scientificas e raciocinadas, para que os alunos tenham uma idéia clara do que se lhes quer ensinar. Educação artística, intelectual e moral: Conhecimento de tudo quanto nos rodeia. Conhecimento das sciencias e das artes. Sentimento do belo, do verdadeiro e do real. Desenvolvimento e compreensão sem esforço e por iniciativa própria. Materias: As materias a serem iniciadas, segundo o alcance das faculdades de cada aluno, constarão de - leitura, caligrafia, gramática, aritmética, geometria, geografia, botânica, zoologia, mineralogia, física, química, fisiologia, história, desenho, etc. Para maior progresso e facilidade do ensino, os meninos exercitar-se-hão nas diversas materias com o auxilio do museu e da biblioteca que esta Escola está adquirindo, e que servirá de complemento ao ensino adquirido nas aulas. Na tarefa de educação tratar-se-há de estabelecer relações permanentes entre a família e a escola, para facilitar a obra dos pais e dos professores. Os meios para criar essas relações serão as reuniões em pequenos festivais, nos quais se recitará, se cantará e se realizarão exposições periódicos dos trabalhos dos alunos; entre os alunos e professores haverá palestras a propósito de varias matérias, onde os pais conhecerão os progressos alcançados pelos alunos. Para complemento do nosso programa de ensino organizar-se-hão sessões artísticas e conferências scientificas. Horário: das 12 da manhã ás 4 da tarde. A inscrição de alunos acha-se aberta das 10 ás 12 horas da manhã e das 4 ás 6 da tarde" (ENSINO Racionalista, 13/12/1913 ${ }^{6}$ - grifos ${ }^{7}$ do autor).

\footnotetext{
${ }^{6} \mathrm{O}$ anúncio reaparece ainda nas edições de 27 de dezembro de 1913 (à página 4) e de 3 de janeiro de 1914 (à página 4).

${ }^{7}$ Os grifos são subtítulos da reportagem/anúncio.
} 
Poucos anos depois da inauguração, as Escolas Modernas brasileiras foram fechadas pela repressão religiosa e política que se valeu de uma “explosão de uma casa, na Rua João Boemer [em outubro de 1919], em que morreram 4 militantes anarquistas, no momento em que manipulavam material explosivo. Entre os mortos, estava o diretor da Escola Moderna de São Caetano, José Alves” (MORAES, 1999, p. 47). Segundo Paulo Ghiraldelli Júnior, “a imprensa conservadora fez questão de concluir que a explosão nada mais era do que um 'erro de cálculo nos planos anarquistas de tomar o poder”” (GHIRALDELLI Jr., 1987, p. 138).

Este contexto no qual se desenrola o fechamento das Escolas Modernas brasileiras é o de exaltação ao nacionalismo que tomava força desde meados da década de 1910. No setor educacional, o movimento, denominado por Nagle, de fervor ideológico "abrangia uma tomada de decisão diante das precárias condições do sistema escolar até então existente, nos seus vários graus e ramos, avançando-se na formulação de uma política nacional de educação” (NAGLE, 1978, p. 261).

Por volta de 1915 , esse fervor transforma-se em entusiasmo ${ }^{8}$, a partir da criação de campanhas e frentes "para desenvolver o sistema escolar e democratizar o acesso ao ensino básico [...] num movimento carregado de idéias cívicas, patrióticas, nacionalistas, onde a questão da difusão da escola popular, a escola primária, aparecia de forma relevante” (GHIRALDELLI Jr., 1987, p. 25). Além disso, o engajamento em ações que visavam a instrução popular e a ampliação do acesso à alfabetização está arraigada na ideia de que “constitui absurdo [...] o fato de que a vontade nacional seja representada por apenas trinta e cinco por cento da população” (NAGLE, 1976, p. 48) - os alfabetizados que podiam votar.

Assim, baseando-se nos "princípios e posturas das elites intelectuais em relação à questão do tema da educação nacional (...) [começou-se também a discutir] a reestruturação interna das escolas, as mudanças dos conteúdos e métodos pedagógicos, a introdução de técnicas pedagógicas com a moderna psicologia” (GHIRALDELLI Jr., 1987, p. 31). Tal discussão sobre a reestruturação interna das escolas abriu as portas para “as idéias da

\footnotetext{
8 “Entusiasmo pela educação”: termo cunhado por Jorge Nagle em 1976. Representa iniciativa de caráter quantitativo, de expansão das escolas. Ocorreu, principalmente, entre os anos de 1887 e 1896, retornando, em sua melhor fase (e a partir da insatisfação dos próprios republicanos com a República existente), após o término da Primeira Guerra Mundial e permanecendo nas duas primeiras décadas do século XX.
} 
Pedagogia Nova, sob o regrário dos escritos de Dewey, Kilpatrick e outros, [que] ganharam força nos anos 20” (GHIRALDELLI Jr., 1987, p. 30) e sucitou a discussão sobre a superação do modelo da "escola tradicional” pelo da "Escola Nova”, ou ativa, em expansão na Europa e nos Estados Unidos.

Assim, a proposta era transformar a educação brasileira em seus métodos, ou seja, destituir a educação do caráter livresco e impregná-la de ativismo, de experimentação. O movimento da Escola Nova aportou em terras brasileiras e desenvolveu-se com a ajuda de intelectuais como Anísio Teixeira e Fernando de Azevedo.

No Brasil, o mais famoso documento alicerçado nesta concepção educacional foi o Manifesto dos Pioneiros da Educação Nova de 1932, mas as teorias escolanovistas podem ser caracterizadas pelos grandes temas da pedagogia do ativismo elencados por Cambi (1999, p. 526/527): o puericentrismo (conceito que coloca a criança como centro do processo educativo); a valorização do "fazer" (que entende o trabalho escolar como atividades manuais, jogo e trabalho produtivo); a motivação (com a ideia de que o interesse da criança deve indicar a atividade pedagógica); a centralidade do "estudo de ambiente" (reforçando a importância da realidade que circunda a criança); a socialização (entendida como “necessidade primária da criança”); o antiautoritarismo (ou seja, o fim da supremacia do adulto e de suas vontades sobre as da criança); e o antiintelectualismo (com a valorização de “uma organização mais livre dos conhecimentos por parte do discente”).

Mais tarde, os conceitos que caracterizam as ações da Escola Nova fundamentaram teoricamente o Construtivismo, disseminado por sua vez, principalmente, pelos estudos de Jean Piaget, retomando "em outras roupagens muitas das idéias fundamentais da escola nova” (DUARTE, 1998, p. 92). É possível, portanto, identificar os temas escolanovistas na teoria construtivista ainda que em termos distintos e/ou em “junções” de um ou mais temas em apenas um conceito.

Exemplo disso é o fato de que, na teoria de Jean Piaget, o sistema de prêmios e castigos representam "apelos a desejos e necessidades fundamentais do educando, com o objetivo de fazê-lo 'aprender' algo que - a seu ver - na ocasião não lhe é vital. É um desvio usado pelo mestre para obter algo irrelevante para o educando” (LIMA, 1980, p. 149). Ou seja, torna-se errôneo premiar ou castigar os alunos pelo próprio motivo de não respeitar a motivação da criança, excluindo-a do centro do processo educativo e de exercitar o 
autoritarismo e o intelectualismo. Em outras palavras é não considerar na prática educativa, quatro dos sete grandes temas do ativismo.

Ainda partindo desse pressuposto, quando o ambiente e o processo educativo não funcionam em respeito às necessidades e à motivação da criança, se tornam ambos estereotipados e não dinâmicos. Além disso, o

homem termina parecendo-se com uma máquina (...) Daí ser preciso que o ambiente humano seja desafiador (diretivismo). O jogo é uma saída operacional para a estereotipia do trabalho padronizado (é por isso que o jogo se opõe ao trabalho). No jogo, procura-se, precisamente, todas as possibilidades do grupo (LIMA, 1980, p. 37).

Piaget difere jogo e trabalho alegando que o primeiro tem por objetivo a diversão e o outro, a técnica. No entanto, embora seja "extremamente frágil a separação entre jogo e técnica” (LIMA, 1980, p. 117), o autor o valoriza como ferramenta de aprendizagem assim como a pedagogia do ativismo.

O próprio processo interno de aprendizagem nos indivíduos evidencia um último exemplo a ser citado aqui. De acordo com a teoria construtivista, cada aprendizado é estruturado em três etapas: assimilação (interpretação da nova informação); acomodação (ruptura, modificação na organização mental do aprendiz); e equilibração (acomodação, reorganização mental que agora engloba a nova informação). Entende-se que para Piaget educação é sinônimo de equilibração e

a inteligência é a flexibilidade que permite novas combinações, segundo um plano de maior equilibração interna e de maior adaptação ao meio. As coordenações e recombinações permitidas por esta flexibilidade, portanto, não são aleatórias. Regem-se pela tendência geral do equilíbrio. Ora a equilibração (movimento no sentido do equilíbrio) supõe que as partes que compõem o todo sejam flexíveis para que o equilíbrio se efetue. Educar pela inteligência, pois, é educar a flexibilidade, isto é, criar situações pedagógicas que exijam recombinações dos esquemas de ação (LIMA, 1980, p. 63 grifos do autor).

As recombinações dos esquemas de ação, o processo de aprendizagem pela tentativa e erro é, na teoria construtivista, assim como na escolanovista, preferível à transmissão de conhecimentos comum à pedagogia tradicional. Reflete-se neste exemplo a valorização da aprendizagem pela experiência, a valorização do fazer.

Essa preferência da experiência à transmissão de conhecimentos no processo educativo constitui o "carro-chefe" da transição do Construtivismo para as teorias pós- 
modernas de educação. "O construtivismo é de tal maneira representativo das tendências ideológicas pós-modernas hoje presentes em educação, que se torna quase a mesma coisa falar em construtivismo e em pensamento educacional pós-moderno” (DUARTE, 2004, p. 90).

Atualmente, o mais conhecido documento que orienta a ação pedagógica no mundo é o relatório da Unesco do ano 2000, redigido por Jaques Dellors e a “Comissão Internacional sobre educação para o século XXI” que estabelece os “Quatro Pilares da Educação” - um conjunto de competências a serem desenvolvidas pelos educandos durante os anos de escolaridade. Entre os pilares, está o “aprender a aprender” ou "aprender a conhecer” que vem transformando o conceito de processo educativo e de metodologia de ensino. Este pilar

visa não tanto a aquisição de um repertório de saberes codificados, mas antes o domínio dos próprios instrumentos do conhecimento pode ser considerado, simultaneamente, como um meio e como uma finalidade da vida humana. Meio, porque se pretende que cada um aprenda a compreender o mundo que o rodeia, (...) finalidade, porque seu fundamento é o prazer de compreender, de conhecer, de descobrir (DELORS, 2000, p. 90/91).

Fundamentados nestes pilares estão também os Parâmetros Curriculares Nacionais brasileiros afirmando que "essas novas relações entre conhecimento e trabalho exigem capacidade de iniciativa e inovação e, mais do que nunca, 'aprender a aprender'” (BRASIL, 2007, p. 28).

\section{Diferenciações necessárias e categorias de análise}

No início deste texto explicamos que alguns fatos nos impedem de almejar qualquer tipo de comparação entre as concepções anarquista, escolanovista, construtivista e pósmoderna de educação. Diante disso e, para reforçar as diferenças que não fugiram às nossas vistas, elaboramos o seguinte quadro para expor as diferenças que impedem comparações e, e ao mesmo tempo, não impedem a análise focada na metodologia de ensino - nosso propósito neste texto. Excluímos do quadro a concepção pós-moderna de educação pelo fato de ela ainda estar se consolidando e ainda confundir-se, em muitos pontos, com a teoria construtivista. 


\begin{tabular}{|c|c|c|c|}
\hline & Anarquismo & Escolanovismo & Construtivismo \\
\hline 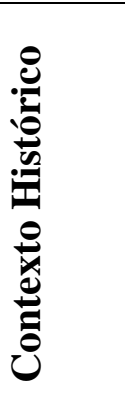 & $\begin{array}{l}\text { Surge no século XVIII e } \\
\text { tem seu maior período } \\
\text { de desenvolvimento na } \\
\text { transição do século XIX } \\
\text { para o XX. }\end{array}$ & $\begin{array}{l}\text { Ápice: terceira e quarta } \\
\text { décadas do século XX. }\end{array}$ & $\begin{array}{l}\text { Nasce entre as décadas } \\
\text { de } 1960 \text { e } 1970 \text { e } \\
\text { perdura até a atualidade. }\end{array}$ \\
\hline 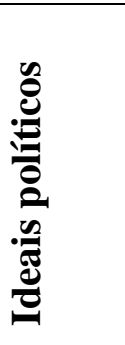 & $\begin{array}{l}\text { Sociedade autorregulada } \\
\text { (superação do sistema } \\
\text { capitalista). }\end{array}$ & $\begin{array}{l}\text { Não superação do } \\
\text { Sistema Capitalista. } \\
\text { As modificações } \\
\text { sociais são } \\
\text { independentes da ação } \\
\text { humana. }\end{array}$ & $\begin{array}{l}\text { Não superação do } \\
\text { Sistema Capitalista. } \\
\text { As modificações sociais } \\
\text { são independentes da } \\
\text { ação humana. }\end{array}$ \\
\hline 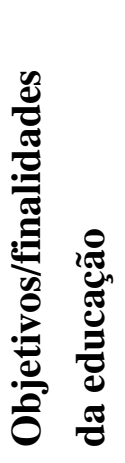 & $\begin{array}{l}\begin{array}{l}\text { Formação da geração } \\
\text { responsável } \\
\text { revolução social. }\end{array} \\
\text { pela }\end{array}$ & $\begin{array}{l}\text { Adaptação à sociedade } \\
\text { Capitalista. } \\
\text { Indivíduo autônomo } \\
\text { que, pela experiência, } \\
\text { dê continuidade e traga } \\
\text { desenvolvimento à } \\
\text { comunidade na qual } \\
\text { está inserido. }\end{array}$ & $\begin{array}{l}\text { Adaptação à sociedade } \\
\text { Capitalista. } \\
\text { Indivíduo autônomo } \\
\text { que, pela experiência, dê } \\
\text { continuidade e traga } \\
\text { desenvolvimento à } \\
\text { comunidade na qual está } \\
\text { inserido. }\end{array}$ \\
\hline
\end{tabular}

Depreende-se do quadro que ao contrário da teoria anarquista, as teorias escolanovista e construtivista nasceram em meio à sociedade capitalista consolidada e não pretendiam superá-la. Ao passo que os anarquistas almejavam a formação da geração responsável pela revolução, as outras teorias consideram mais importante a preparação para a vida na sociedade que é dinâmica, não atribuindo seu dinamismo à ação humana. Com as diferenciações necessárias postas, passemos à análise dos procedimentos metodológicos defendidos e utilizados pelas teorias citadas.

A primeira categoria de análise identificada refere-se à importância da psicologia infantil no processo educativo. Em 1908, a Liga Internacional para a Educação Racionalista da Criança, criada com a participação de Francisco Ferrer y Guardia, já reivindicava "que os programas e métodos de ensino estivessem adaptados á psicologia da criança” (CALSAVARA, 2004, p. 30). Ferrer defendia 
uma educação baseada na evolução real e psicológica do indivíduo, uma educação individualizada. $\mathrm{O}$ conhecimento científico sobre $\mathrm{o}$ desenvolvimento espontâneo das faculdades da criança deveria ser usado a seu favor a fim de que esta pudesse buscar livremente a satisfação de suas necessidades físicas, intelectuais e morais (CALSAVARA, 2004, p. 31).

As teorias anarquistas viam, dessa forma, o aluno como o centro do processo educativo, e

essa freqüente preocupação com a valorização da criança, em todos os sentidos, merece destaque na atuação educacional dos libertários. A criança era entendida como um ser possuidor de vontades próprias e não uma mera reprodutora dos gestos dos adultos (CALSAVARA, 2004, p. 196).

Na teoria escolanovista, a importância da psicologia infantil e a valorização do aluno enquanto centro do processo educativo aparece nos temas da pedagogia do ativismo sob os conceitos do puericentrismo e da motivação.

Para os construtivistas, cujas ideias de psicologia infantil estão mais maduras, respeitar os estágios de desenvolvimento do aluno é ter como direcionamento do trabalho o próprio aluno, o desenvolvimento do sujeito central do processo educativo: a criança.

A segunda categoria de análise trabalhada é a do jogo como ferramenta de aprendizagem. Para Francisco Ferrer, “a ação da criança durante o jogo antecipa a ação do adulto no trabalho” (CALSAVARA, 2004, p. 36). Anarquistas e escolanovistas valorizam a espontaneidade da criança "solicitando a educação sensório-motora e intelectual através de formas adequadas, o jogo, da livre atividade, do desenvolvimento afetivo, da socialização” (MANACORDA, 2002, p. 305) permitindo que “o processo de aprendizagem (...) [seja] prazeroso, com atividades lúdicas, jogos, valorizando diferentes espaços” (CALSAVARA, 2004, p. 196). Mais especificamente, a teoria escolanovista trata deste conceito nos temas da valorização do fazer e no antiintelectualismo, já que a apropriação mais livre dos conhecimentos pelo discente favorece a exploração do lúdico no processo educativo.

Na concepção construtivista especula-se que "um dia, provavelmente, o conceito de educação estará estritamente ligado ao de jogo” (LIMA, 1980, p. 118/119), com o cuidado de evitar ao máximo que a atividade lúdica se transforme em técnica - assim como também alertava o anarquista Stirner. Segundo este, quando “o Saber é colocado a serviço da técnica, do progresso econômico, da humanidade abstrata: já não é mais questão de verdadeira cultura, de vontade livre, nem de personalidade” (BARRUÉ, 2001, p. 48). 
Nossa terceira categoria decorre desta segunda já que se trata do conceito de experiência como atividade fundamental. Ou seja, passa-se a idéia de que experienciar o aprendizado enriquece o desenvolvimento da criança e tal experiência pode se dar através do jogo. Além da atividade lúdica, os anarquistas ressaltavam ser importante basear o conhecimento "na experiência, na observação direta e na descoberta individual e não em aulas cansativas, onde frases e textos eram mecanizados, repetidos, decorados acusando um ensino sem sentido” (CALSAVARA, 2004, p. 196). Mais uma vez, vemos intrínseca relação com a valorização do fazer e com o antiintelectualismo. De acordo com Manacorda, a teoria escolanovista objetivava uma educação

onde não existiam mais traços de métodos de ensino através de palavras que não fossem traduzidas em atos pelos alunos e onde os alunos eram treinados para encontrar sozinhos as verdades, a resolver sozinhos os problemas científicos; onde, enfim, o critério fundamental era aprender fazendo, o learning by doing (MANACORDA, 2002, p. 309 - grifos do autor).

O conceito de experiência também não foge às vistas da concepção construtivista que valoriza ambientes que permitam o contato dos alunos com objetos que, além de favorecer o aprendizado, estimulem o desenvolvimento das crianças de acordo com o estágio em que se encontram.

Ampliando essa noção de ambiente e saindo dos muros da escola, passamos à nossa quarta categoria de análise: a importância do meio no qual o aluno está inserido. Importante ressaltar que pode-se interpretar essa temática como preparação para a ação futura dos alunos no meio social e como presença da comunidade no ambiente escolar. Sobre a primeira interpretação, pode-se pensar que as diferenças descritas no início desta análise impediriam aproximações, no entanto, embora o conceito de democracia seja extremamente distinto entre as teorias, anarquistas e piagetianos concordam que “o objetivo é a liberdade com respeito mútuo e com normas livremente deliberadas. Os pais devem esclarecer os filhos que a liberdade não é fazer o que se quer, mas participar ativamente da elaboração das normas comuns” (LIMA, 1980, p. 48).

Sobre a segunda possibilidade de interpretação, Francisco Ferrer propôs na $L a$ Escuela Moderna, conferências semanais para instruir a comunidade acerca de assuntos de interesse comum (como higiene e saúde, por exemplo) que ganharam força e estabeleceram-se como cursos científicos. Aliado aos cursos, a metodologia anarquista propõe os "estudos de 
meio”, ou seja, passeios pelos entornos da escola para que se possa observar in loco conteúdos aprendidos em sala de aula. Segundo relatos destes passeios, os alunos também faziam piqueniques estimulando a sociabilização entre as crianças.

Mais uma vez recorremos aos grandes temas da pedagogia do ativismo, que orienta os escolanovistas, lembrando-nos dos conceitos de socialização e centralidade do estudo de ambiente. Nas teorias construtivistas, a construção do conhecimento favorecida pela interação entre crianças e meio ambiente dá as bases para o conceito de adaptação - fundamental na teoria do biólogo suíço. Piaget “interpretava o desenvolvimento da inteligência como parte do processo de adaptação do indivíduo ao meio ambiente, numa direta referência ao processo biológico de interação adaptativa entre organismos e meio ambiente” (DUARTE, 2004, p. 91). Importante lembrar que a citada interação adaptativa entre organismos, refere-se também à interação entre indivíduos.

Por fim, a última categoria identificada por nós no decorrer da pesquisa - e que está estritamente ligada ao conceito de interação entre os indivíduos - é o do papel do professor. É inegável o fato de que, ao nos tornarmos estudantes, interagimos, em primeiro lugar com o professor. Segundo os anarquistas, o professor "deve facilitar os meios para (...) os conhecimentos mais essenciais a fim de que eles próprios criem sua educação" (CALSAVARA, 2004, p. 154/155). Tal conceito nos parece muito próximo ao das teorias escolanovistas e construtivistas, para as quais o professor também deve atuar como orientador e facilitador do processo de aprendizagem. No caso da Escola Nova, esse conceito está claro no tema do antiautoritarismo.

Sobre o melhor momento de interferência do professor, os anarquistas sugerem que “o professor deveria ser um observador, saber aproveitar os momentos adequados, para que o aluno descobrisse por si mesmo, os fenômenos presentes a sua volta” (CALSAVARA, 2004, p. 196). Dewey ainda explica que o professor tem a função de “determinar o ambiente, o meio necessário à criança e, assim, dirigir indiretamente sua atividade mental” (DEWEY, 1978, p. 61). Aqui a proximidade das teorias é nítida já que, segundo as citações indicadas, o conceito pós-moderno de “aprender a aprender”, assim como os estágios do desenvolvimento (nos quais o professor deve atuar) para que o aluno descubra por si mesmo os novos conhecimentos, com o auxílio e a direção do professor, não são, necessariamente, adventos do século XX, mas perpassam de igual forma as ideias anarquistas. 
No entanto, uma diferença é passível de exposição: O professor da teoria construtivista vê o conhecimento construído pelo aluno como verdade, ainda que momentânea. Ainda que o aluno esteja errado, o professor não o corrige já que, o próprio aluno o fará ao passo que avançar no processo de construção do conhecimento revendo os conceitos elaborados anteriormente. Já na teoria anarquista, o professor dirige ao invés de supervisionar o processo de aprendizagem questionando "as grandes verdades apresentadas na escola oficial sem preocupações de qualquer espécie e sem olhar as conseqüências” (CALSAVARA, 2004, p. 154/155 - grifos da autora). Vê-se assim, uma atuação mais direta do educador na construção do conhecimento do aluno.

\section{Considerações finais}

Pudemos perceber, ao longo do texto, o quanto a educação, em todas as épocas, possui um forte caráter político, por, ao mesmo tempo, representar uma das instâncias da sociedade que é responsável por sua manutenção e apresenta um potencial transformador.

Não podemos afirmar que as teorias anarquistas fundamentaram metodologicamente o movimento da Escola Nova. No entanto, vimos que o contexto histórico do fechamento das instituições anarquistas brasileiras foi o mesmo que recebeu e favoreceu o desenvolvimento das teorias e iniciativas dos escolanovistas. Em seguida, construtivistas parecem ter reavivado metodologias existentes e defendidas desde o século XIX pelos anarquistas divulgando-as e defendendo-as como inovadoras. E se as metodologias são renovadas no decorrer da história, podemos dizer que o objetivo também continua muito parecido: (ainda) pretende-se superar o caráter livresco, intelectualizado da educação tradicional, pela ludicidade e autonomia do “aprender a aprender”. De acordo com Duarte,

do ponto de vista didático, o pensamento educacional burguês nunca superou a oposição entre a escola tradicional e a escola nova. Essa oposição foi reeditada pelo construtivismo, o qual repetiu a estratégia, já usada pelos escolanovistas, de apresentar a escola tradicional como "portadora de todos os defeitos e nenhuma virtude” (DUARTE, 2005, p. 208).

Nesta busca histórica pela superação da educação tradicional, anarquistas, escolanovistas e construtivistas valorizam a criança como sujeito central do processo educativo assim como o jogo, o lúdico, como ferramenta de aprendizagem. Além disso, as 
três teorias procuram, em suas metodologias, estimular a experimentação para que a construção do conhecimento no aluno se dê de forma mais concreta e significativa. Também procuram preparar o indivíduo para atuar na sociedade enquanto cidadão autônomo, cumpridor de deveres e ciente de seus direitos (ainda que o conceito de sociedade ideal das teorias fosse muito distinto). Por fim, todas as teorias analisadas (talvez por terem como foco central do processo educativo a criança), compreendem a atuação do professor como elemento de mediação, de direção e não de transmissão.

No entanto, este movimento parece estar gerando consequências e, a que consideramos mais grave, é a da contribuição para o detrimento do papel e da atuação docente. Subjugar as ações do educador ao aluno e suas vontades parece gerar uma inversão de papéis.

\begin{abstract}
De nossa parte não discordamos da afirmação de que a educação escolar deva desenvolver no indivíduo a capacidade iniciativa de buscar por si mesmo novos conhecimentos, a autonomia intelectual, a liberdade de pensamento e de expressão. Nosso ponto de discordância reside na valoração, contida no "aprender a aprender", das aprendizagens que o indivíduo realiza sozinho como mais desejáveis do que aquelas que ele realiza por meio da transmissão de conhecimentos por outras pessoas. Não concordamos que o professor, ao ensinar, ao transmitir o conhecimento, esteja cerceando o desenvolvimento da autonomia e da criatividade dos alunos (DUARTE, 2004, p. 35).
\end{abstract}

Essa inversão de papéis parece também estar, consequentemente, favorecendo o detrimento do próprio conceito de processo educativo. Consideramos clássico na educação o processo de transmissão e assimilação dos conceitos histórica e socialmente acumulados. “A rejeição do que é clássico na educação escolar significa assumir uma atitude negativa em relação ao ato de ensinar. Nesse ponto reside o aspecto mais problemático da crítica escolanovista/construtivista à escola tradicional: a negação da própria essência do trabalho educativo” (DUARTE, 2005, p. 209).

Assim, esperamos ter contribuído para a discussão acerca da História da Educação brasileira e das metodologias utilizadas nas instituições de ensino. Concluímos do caminho traçado e da análise feita que sim, uma metodologia educacional pode ser utilizada por duas ou mais teorias educacionais, ainda que distintas em relação aos objetivos finais da educação e às suas bases ideológicas. Ou seja, a metodologia anarquista de educação, a forma como os 
anarquistas conduziam o processo educativo é extremamente atual se pensarmos no que se dissemina como “moderno” na educação contemporânea.

\section{Referências Bibliográficas}

BARRUÉ, Jean. Da educação. In: STIRNER, Max. O falso princípio da nossa educação. Tradução de Plínio Augusto Coêlho. pp. 23-58. São Paulo: Imaginário, 2001.

BRASIL. Parâmetros Curriculares Nacionais. Documento Introdutório. 1997. Disponível em: <http://portal.mec.gov.br/seb/arquivos/pdf/livro01.pdf>. Acesso em 11/05/2007.

CALSAVARA, Tatiana da S. Práticas da Educação Libertária no Brasil - A Experiência da Escola Moderna em São Paulo. Dissertação (Mestrado em História da Educação e Historiografia) - Faculdade de Educação, Universidade de São Paulo, São Paulo, 2004.

CAMBI, Franco. História da Pedagogia. Tradução de Álvaro Lorencini. São Paulo: Editora da Unesp, 1999.

DELORS, Jacques. Os quatro pilares da educação. In: Educação: um tesouro a descobrir. pp. 89-101. São Paulo: Cortez, Brasília, DF: Unesco, 2000.

DEWEY, John. Vida e Educação. Biblioteca de Educação. Série Iniciação e debate. São Paulo: Editora Melhoramentos, 1978.

DUARTE, Newton. Concepções afirmativas e negativas sobre o ato de ensinar. Caderno Cedes. n. 44. ano XIX. pp. 85-106. Campinas, 1998.

DUARTE, Newton. Por que é necessária uma análise crítica marxista do construtivismo? In: LOMBARDI, José C. \& SAVIANI, Dermeval (orgs.) Marxismo e Educação - debates contemporâneos. Campinas: Autores Associados/Grupo de Pesquisa História Sociedade e Educação no Brasil (HISTEDBR), 2005.

DUARTE, Newton. Vigotski e o “aprender a aprender": crítica às apropriações neoliberais e pós-modernas da teoria vigotskiana. 3. ed. Campinas, SP: Autores Associados, 2004. 
ESCOLA da Ponte. Projeto Pedagógico: Fazer a Ponte. Disponível em: <http://www.eb1ponte-n1.rcts.pt/>. Acesso em 20/08/2007.

FERRER, Christian. Max Stirner, autor de um único livro. In: STIRNER, Max. O falso princípio da nossa educação. Tradução de Plínio Augusto Coêlho. pp. 15-20. São Paulo: Imaginário, 2001.

GHIRALDELLI Jr., Paulo. Educação e movimento operário. São Paulo: Cortez/ Autores Associados, 1987.

LIMA, Lauro de Oliveira. Piaget para principiantes. 8. v. Coleção Novas Buscas em Educação. São Paulo: Summus, 1980.

MANACORDA, Mario A. História da Educação - da Antigüidade aos nossos dias. Tradução de Gaetano Lo Monaco. 10. ed. São Paulo: Cortez, 2002.

MORAES, José Damiro de. A trajetória educacional anarquista na Primeira República: das escolas aos centros de cultura social. Dissertação de Mestrado, Universidade Estadual de Campinas. Campinas/SP: Unicamp, 1999.

MORAES, José Damiro de. Francisco Ferrer y Guardia. Verbete elaborado para o glossário on-line do sítio do Grupo de Pesquisa História Sociedade e Educação no Brasil (HISTEDBR). Disponível em: <http://www.histedbr.fae.unicamp.br/navegando/ glossario/verb_b_francisco_ferrer_y_guardia1.htm>. Acesso em 15/03/2009.

NAGLE, Jorge. A educação na primeira república. In: FAUSTO, Boris (dir.) História Geral da Civilização Brasileira. Tomo III - O Brasil Republicano - Sociedade e Instituições (18891930). 2. ed. v. 2. São Paulo: Difel, 1978.

NAGLE, Jorge. Educação e sociedade na primeira república. São Paulo: EPU, 1976.

PROUDHON, Pierre-Joseph. A propriedade é um roubo e outros escritos anarquistas. Seleção e notas de Daniel Guérin. Tradução de Suely Bastos. 84. v. Coleção L\&PM Pocket. Porto Alegre: L\&PM, 1998.

STIRNER, Max. O falso princípio da nossa educação. Tradução de Plínio Augusto Coêlho. São Paulo: Imaginário, 2001. 
 \\ 14tmerarius Reflectionis

TOLSTOI, L.N. Obras Pedagógicas. Tradução de J. M. Milhazes Pinto. Impresso na URSS. Edições Progresso, 1988.

WOODCOCK, George. História das idéias e movimentos anarquistas. v. 1 - A idéia. Tradução de Julia Tettamanzy. v. 273. Coleção L\&PM Pocket. Porto Alegre: L\&PM, 2002.

\section{Periódicos}

ENSINO Racionalista. A Lanterna. São Paulo. Edição de 13/12/1913. 